\title{
Subclinical thyroid dysfunction and autoantibodies in acute ischemic and hemorrhagic stroke patients: relation to long term stroke outcome
}

\author{
Rania S. Nageeb ${ }^{1 *}$ (D), Amr M. Azmy², Heba F. Tantawy ${ }^{1}$, Ghada S. Nageeb and Alaa A. Omran
}

\begin{abstract}
Background: Data regarding the relation between both subclinical thyroid dysfunction, thyroid autoantibodies and clinical outcomes in stroke patients are limited. This study aimed to evaluate subclinical thyroid dysfunction and thyroid autoantibodies production in acute stroke patients and their relation to long term stroke outcome. We recruited 138 patients who were subjected to thorough general, neurological examination and brain imaging. Blood samples were collected for measurement of levels of serum thyroid function [free tri-iodothyronine (FT3), free thyroxin (FT4), thyroid stimulating hormone (TSH)], thyroid autoantibodies within $48 \mathrm{~h}$ after hospital admission. FT4 and TSH after 1 year were done. The stroke severity was assessed at admission by the National Institutes of Health Stroke Scale (NIHSS). The stroke outcome was assessed at 3 months and after 1 year by the modified Rankin Scale (mRS). We divided the patients into two groups according to thyroid autoantibodies (positive and negative groups).

Results: Subclinical hyperthyroidism was found in $23 \%$ of patients, and subclinical hypothyroidism in $10 \%$ of patients. Euthyroidism was detected in $67 \%$ of patients. $34 \%$ patients had positive thyroid autoantibody. Positive thyroid autoantibodies were commonly found in those with subclinical hyperthyroidism (28\%), followed by subclinical hypothyroidism (21\%) and euthyroidism (14\%). $73 \%$ and 59\% of stroke patients had poor outcomes (mRS was $>2$ ) at 3 months and 1 year respectively with no significant difference between ischemic and hemorrhagic stroke patients. In the positive group final TSH level, NIHSS score at admission, and disability at 1 year were significantly higher compared with the negative group. Poor outcome was significantly associated with higher NIHSS score at admission, positive thyroid autoantibodies, subclinical hyperthyroidism, and atrial fibrillation.
\end{abstract}

Conclusions: Subclinical thyroid dysfunction could be found in stroke patients with positive thyroid autoantibodies. Subclinical hyperthyroidism and thyroid autoantibodies were associated with a poor outcome at 1 year in first-ever acute stroke patients especially in those presented with atrial fibrillation and higher NIHSS score at admission.

Keywords: Tri-iodothyronine, Thyroxin, Thyroid stimulating hormone, Thyroid antibodies, Cerebral stroke, NIHSS, mRS

*Correspondence: rnsanad@yahoo.com

${ }^{1}$ Faculty of Medicine, Zagazig University, Zagazig, Sharkia, Egypt

Full list of author information is available at the end of the article

\section{Background}

Stroke is one of the most frequent causes of morbidity and mortality worldwide with a significant clinical and socioeconomic impact [1]. Several variables affect stroke prognosis. Knowledge of the variables contributing to early neurologic deterioration after stroke can guide the 
early management strategies and lead to more favorable outcomes [2].

Thyroid autoimmunity is a common disorder resulting in dysfunction (hypo-or hyper function) of thyroid gland. Thyroid autoimmunity, especially antithyroperoxidase antibody may be associated with the development of intracranial stenosis, moyamoya disease and arterial dissection [3-5]. These findings have been attributed to immune-mediated inflammatory reaction and resultant endothelial dysfunction on the cerebral vasculature, based on the fact that vascular tissues share some antigenic properties with thyroid tissues [6].

Subclinical thyroid dysfunction is a common condition among general population, including a prevalence reaching up to $15 \%$ for subclinical hypothyroidism, and $12 \%$ for subclinical hyperthyroidism [7-10]. The cardiocerebral vascular system is one of the major targets of thyroid hormones [7]. Subclinical hypothyroidism has been found to propagate vascular risk factors, such as hyperlipidemia [11], metabolic syndrome [12] and vascular stiffness [13]. Subclinical hyperthyroidism has been proved to promote vascular damage by facilitating hypertension, maintaining hypercoagulable state and causing endothelial dysfunction [14, 15].

It is always good to repeat the thyroid function tests in subclinical thyroid dysfunction for confirmation or to rule out an erroneous report. Also, there is another important reason to repeat tests after a period of time because in a proportion of participants spontaneous resolution of thyroid dysfunction can occur [16]. Levels of TSH normalized after the first repeated measurement during the subsequent month in about $60 \%$ of patients. Normalization of patients with subclinical hypothyroidism occurred at a median time of 18 months [17].

Previous studies have evaluated the association between subclinical thyroid dysfunction and the prognosis after acute ischemic stroke, with conflicting conclusions $[18,19]$. However, the association between both subclinical thyroid dysfunction and autoantibodies production with the outcome of stroke in patients with acute cerebral stroke (ischemic and hemorrhagic) has not been examined closely.

The aim of this study was to evaluate subclinical thyroid dysfunction and autoantibodies [thyroid peroxidase autoantibodies (TPO-Ab) and thyroglobulin autoantibodies (TG-Ab)] production in acute ischemic and hemorrhagic stroke patients and their relation to long term stroke outcome.

\section{Methods}

This is a prospective cohort study conducted in the period from May 2020 to May 2021. 152 patients meeting the inclusion criteria of this study and admitted in the stroke units, intensive care units of departments of neurology and internal medicine in Zagazig University hospitals during this period were included in the study. Five patients died within 3 days after admission, six patients had recurrent stroke during the period of 1 year follow up and three patients missed in the follow up visit, so only 138 were included in the study. An informed consent was obtained from all participants within the study. Ethical committee of Zagazig University approved for performing this study.

Any acute cerebral stroke (ischemic or hemorrhagic) patients with first-ever acute onset stroke were eligible for the study. We excluded participants with history of hepatic and renal failure; recurrent cerebrovascular stroke; brain malignancy; known disease of the thyroid gland, or medications affect function of the thyroid (such as lithium, and glucocorticoids); endocrinal disease, inflammatory, infectious diseases; thyroid surgery, $\mathrm{I}^{131}$ or thyroid hormone replacement therapy within the past.

All participants of the current study were submitted to full neurological history taking, detailed general and neurological examinations with paying special attention on neck and thyroid examination.

Computed tomography (CT) using GE ProSpeed Dual Slice F II CT, MX135 Tube (Cleveland, USA) and/ or magnetic resonance imaging using 1.5T MR Scanner (Achieva, Philips Medical System) of the brain was done on admission to differentiate cerebral infarction from hemorrhage and to determine the size and site of the brain lesion. Another CT scan or magnetic resonance imaging was performed when there was no positive data on the admission $\mathrm{CT}$ scan and when the participants met the diagnosis of recurrent cerebral stroke with a new focal neurologic deficit to detect the corresponding lesion on the imaging scan. The size of lesion was determined by the largest diameter of the lesion [20].

We collected routine laboratory investigation from patients' files. We obtained one venous blood sample from each participant within $48 \mathrm{~h}$ of stroke onset to measure free tri-iodothyronine (FT3), free thyroxin (FT4), thyroid stimulating hormone (TSH), thyroid autoantibodies. Also, FT4 and TSH were measured after 1 year.

Blood samples were collected by venipuncture from an antecubital vein before breakfast at about eight A.M. Centrifugation of the blood was done, serums were removed and stored at $2-8{ }^{\circ} \mathrm{C}$ until testing could be performed. If the sample was not tested within $8 \mathrm{~h}$ of collection, it was stored at $-70{ }^{\circ} \mathrm{C}$ and tested within 1 month. FT3, FT4, TSH were measured by electrochemiluminescence immunoassay [Cobas e411, Roche, Japan]. 
Normal TSH levels was defined as $0.3-5.0 \mathrm{mIU} / \mathrm{mL}$, normal FT3 was 3.5-6.5 pmol/L, normal FT4 was 11.9$26.0 \mathrm{pmol} / \mathrm{L}[3,21]$.

Euthyroidism was defined as normal TSH $(0.3-5.0$ $\mathrm{mIU} / \mathrm{mL})$, free $\mathrm{T}_{3}\left(\mathrm{FT}_{3}\right)$ and $\mathrm{FT}_{4}$. Clinical hypothyroidism was diagnosed as increased TSH $(>5.0 \mathrm{mIU} / \mathrm{mL})$ and suppressed $\mathrm{FT}_{3}$ and $\mathrm{FT}_{4}$; subclinical hypothyroidism had increased TSH $(>5.0 \mathrm{mIU} / \mathrm{mL})$ with normal $\mathrm{FT}_{4}$. Clinical hyperthyroidism was defined as low TSH $(<0.3 \mathrm{mIU} / \mathrm{mL})$ with elevated $\mathrm{FT}_{3}$ and $\mathrm{FT}_{4}$; subclinical hyperthyroidism was diagnosed as low TSH $(<0.3 \mathrm{mIU} / \mathrm{mL})$ and normal $\mathrm{FT}_{4}[22]$.

Serum thyroid autoantibodies were analyzed by enzyme linked immunosorbent assay for the determination of thyroid peroxidase autoantibodies and thyroglobulin autoantibodies in human serum (GenWay Biotech, Inc).

Purified thyroglobulin antigen is bound to the wells of a polystyrene microwell plate under conditions which will preserve the human thyroglobulin antigen in its native status. Diluted sera of the patient are added to separate these wells, allowing any thyroglobulin autoantibodies present to bind to the immobilized thyroglobulin antigen. Unbound venous sample is washed away, and an enzyme labeled anti-human IgG conjugate is added to every well. Incubation allows the enzyme labeled anti-human IgG to bind to any antibodies of the patient, which became attached to the microwells. Then, after washing away any unbound enzyme labeled anti-human IgG, the remaining enzyme activity is measured by adding a chromogenic substrate and measuring the color intensity that develops within the wells.

Normal ranges for thyroid peroxidase autoantibodies was defined as $0-60 \mathrm{IU} / \mathrm{mL}$ and normal thyroglobulin autoantibodies was $0-60 \mathrm{IU} / \mathrm{mL}$ [23]. We divided the stroke patients into two groups according to thyroid autoantibodies. Positive thyroid autoantibody group was defined as either thyroglobulin autoantibodies or thyroid peroxidase autoantibodies $\geq 60 \mathrm{IU} / \mathrm{mL}$. Negative thyroid autoantibody group was defined as thyroglobulin autoantibodies and thyroid peroxidase autoantibodies of less than $60 \mathrm{IU} / \mathrm{mL}$.

The severity of the stroke was assessed by using the National Institutes of Health Stroke Scale (NIHSS) at admission. Severity of stroke was categorized as mild (NIHSS score $<8$ ), moderate (NIHSS score from 8 to 14), and severe stroke (NIHSS score $\geq 15$ ) [24].

Assessment of functional outcome at 3 months and after 1 year of stroke onset was done by using the modified Rankin Scale (mRS) that evaluates the global disability or restriction on daily activities on a 7-point scale. It consists of six grades, with the best score is zero (when no symptoms present), the worst scores are five (when severe disability present and require constant care), and six (being dead). Poor functional outcome of stroke patients was defined as death or disability (mRS scores $\geq$ two) [25]. The mRS was performed through the follow up visits.

Both assessment of neurological outcome, severity of all included participants within the study was performed by the neurologist blinded to levels of thyroid hormones and autoantibodies.

\section{Statistical analysis}

The data collected of this study were statistically analyzed using the Statistical Package of Social Science (SPSS) program for Windows version 24 (Released 2016 by International Business Machines Corporation, USA). Categorical variables were expressed as percentages and numbers, whereas continuous data were expressed as mean \pm standard deviation (SD). Student $t$ test or Chisquare test was used to compare between both groups as deemed appropriate. Independent factors associated with long term outcome in patients presented with firstever acute stroke was identified by performing multiple regression analysis and logistic regression analysis. $P$ value less than $0.001,0.05$ was considered as highly significant and significant, respectively.

\section{Results}

This cross-sectional study included 138 stroke patients with a mean age $( \pm S D)$ of 64.71 years $( \pm 12.64) .108$ (78\%) of our patients had ischemic stroke and $30(22 \%)$ patients had intracerebral hemorrhage. Of the 138 patients, 47 (34\%) were of the thyroid autoantibody positive group. $34(72 \%)$ patients presented with acute firstever ischemic stroke were of the thyroid autoantibody positive group. $13(28 \%)$ patients presented with acute first- ever intracerebral hemorrhage were of the thyroid autoantibody positive group (Table 1).

Subclinical thyroid dysfunction among the stroke patients was found in $46(33 \%)$ patients. Subclinical hyperthyroidism was found in $32(23 \%)$ patients, and subclinical hypothyroidism in $14(10 \%)$ patients. Euthyroidism was detected in $92(67 \%)$ patients. The patients with positive thyroid autoantibodies were commonly found in those with subclinical hyperthyroidism (28\%), followed by subclinical hypothyroidism (21\%) and euthyroidism (14\%).

The baseline demographics, and laboratory results including thyroid function test of both thyroid autoantibody positive and thyroid autoantibody negative groups are shown in Table 1. Higher final TSH level and higher NIHSS score at admission was significantly observed in the thyroid autoantibody positive group than the thyroid autoantibody negative group $(P=0.04,0.001$ 
Table 1 Comparison of clinical parameters of acute stroke patients with positive thyroid autoantibody and those with negative thyroid autoantibody

\begin{tabular}{|c|c|c|c|}
\hline \multirow[t]{2}{*}{ Variables } & \multicolumn{2}{|c|}{ Thyroid autoantibody } & \multirow[t]{2}{*}{$P$ value } \\
\hline & Positive $(N=47)$ & Negative $(N=91)$ & \\
\hline Age, years & $64.17 \pm 12.46$ & $64.55 \pm 10.3$ & 0.85 \\
\hline \multicolumn{4}{|l|}{ Sex } \\
\hline Male, $n(\%)$ & $21(45 \%)$ & $39(43 \%)$ & 0.82 \\
\hline Female, $n(\%)$ & $26(55 \%)$ & $52(57 \%)$ & \\
\hline $\mathrm{SBP}, \mathrm{mmHg}$ & $116.9 \pm 12.5$ & $118.43 \pm 12.23$ & 0.49 \\
\hline $\mathrm{DBP}, \mathrm{mmHg}$ & $76.2 \pm 7.9$ & $77.3 \pm 9.2$ & 0.49 \\
\hline $\mathrm{TC}, \mathrm{mmol} / \mathrm{L}$ & $5.20 \pm 1.12$ & $5.26 \pm 1.13$ & 0.77 \\
\hline LDL-C, mmol/L & $3.37 \pm 0.57$ & $3.31 \pm 0.81$ & 0.65 \\
\hline $\mathrm{HDL}-\mathrm{C}, \mathrm{mmol} / \mathrm{L}$ & $1.22 \pm 0.36$ & $1.17 \pm 0.32$ & 0.41 \\
\hline $\mathrm{TG},(\mathrm{mg} / \mathrm{dL})$ & $138.8 \pm 76.2$ & $127.8 \pm 62.42$ & 0.58 \\
\hline $\begin{array}{l}\text { Initial free T4 level } \\
\text { (pmol/L) }\end{array}$ & $13.7 \pm 2.7$ & $14.01 \pm 2.4$ & 0.49 \\
\hline $\begin{array}{l}\text { Final free T4 level } \\
(\mathrm{pmol} / \mathrm{L})\end{array}$ & $14.9 \pm 3.2$ & $14.4 \pm 3.1$ & 0.37 \\
\hline Free T3 level (pmol/L) & $4.11 \pm 0.75$ & $4.19 \pm 0.73$ & 0.55 \\
\hline $\begin{array}{l}\text { Initial TSH level (mIU/ } \\
\mathrm{mL} \text { ) }\end{array}$ & $1.64 \pm 1.08$ & $1.62 \pm 1.13$ & 0.92 \\
\hline $\begin{array}{l}\text { Final TSH level (mIU/ } \\
\mathrm{mL} \text { ) }\end{array}$ & $3.98 \pm 0.58$ & $3.74 \pm 0.69$ & $0.04^{*}$ \\
\hline \multicolumn{4}{|l|}{ Type of stroke } \\
\hline Ischemic infarction & $34(72 \%)$ & $74(81 \%)$ & \\
\hline $\begin{array}{l}\text { Intracerebral hem- } \\
\text { orrhage }\end{array}$ & $13(28 \%)$ & $17(19 \%)$ & 0.23 \\
\hline $\begin{array}{l}\text { NIHSS score at } \\
\text { admission }\end{array}$ & $10 \pm 5$ & $8 \pm 2$ & $0.001^{* *}$ \\
\hline
\end{tabular}

$B M I$ body mass index, SBP systolic blood pressure, DBP diastolic blood pressure, $T C$ total cholesterol, LDL-C low-density lipoprotein cholesterol, HDL-C highdensity lipoprotein cholesterol, $T G$ triglycerides, $T 3$ tri-iodothyronine, $T 4$ thyroxin, TSH thyroid stimulating hormone, NIHSS National Institute of Health Stroke Scale

Continuous data are represented in mean \pm standard deviation; categorical data are represented in number and percentage

**Highly significant

respectively). The serum FT3, FT4, TSH levels and type of stroke did not differ between both groups.

The percentages of ischemic and hemorrhagic stroke patients who had poor outcomes (mRS was $>2$ ) at 3 months and 1 year were $73 \%$ and $59 \%$ respectively with no significant difference between ischemic and hemorrhagic stroke patients (Fig. 1).

As regard to clinical outcomes after 1 year of acute stroke patients, we found that disability $(P=0.001)$ in the thyroid autoantibody positive group was significantly higher compared with the thyroid autoantibody

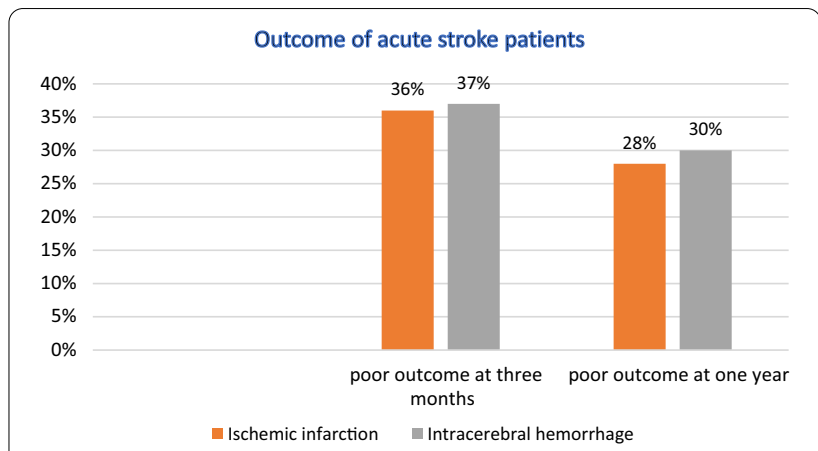

Fig. 1 Outcome of ischemic and hemorrhagic stroke patients at 3 months and after 1 year of stroke onset

Table 2 Relation between thyroid autoantibody and poor outcomes after 1 year in acute stroke patients

\begin{tabular}{llcl}
\hline $\begin{array}{l}\text { Poor outcomes after } \\
\text { 1 year in acute stroke } \\
\text { patients }\end{array}$ & \multicolumn{2}{l}{ Thyroid autoantibody } & P value \\
\cline { 2 - 3 } & Positive $(\boldsymbol{N = 4 7 )}$ & Negative $(\boldsymbol{N = 9 1 )}$ & \\
\hline Mortality & $10(10 \%)$ & $4(8 \%)$ & 0.69 \\
$\begin{array}{l}\text { Disability (mRS } \\
\text { scores } \geq \text { two) }\end{array}$ & $29(62 \%)$ & $30(33 \%)$ & $0.001^{* *}$ \\
\hline **Highly significant & & & \\
\hline
\end{tabular}

Table 3 Multiple regression analysis for predictors of poor outcome at 1 year among acute stroke patients

\begin{tabular}{lll}
\hline $\begin{array}{l}\text { Predictors of poor outcome at one } \\
\text { year among acute stroke patients }\end{array}$ & OR $(\mathbf{9 5 \%} \mathrm{Cl})$ & $\boldsymbol{P}$-value \\
\hline Older Age & $0.11(1.04-2.81)$ & $0.01^{*}$ \\
Hypertension & $2.89(1.82-10.15)$ & $0.04^{*}$ \\
Atrial fibrillation & $1.32(1.23-6.45)$ & $0.02^{*}$ \\
Hyperlipidemia & $3.59(0.24-10.38)$ & 0.11 \\
Current smoking & $1.62(0.71-3.69)$ & 0.25 \\
Subclinical hypothyroidism & $0.97(0.28-3.33)$ & 0.96 \\
Subclinical hyperthyroidism & $2.51(1.02-6.15)$ & $0.04^{*}$ \\
Higher NIHSS score at admission & $18.51(1.60-29.31)$ & $0.001^{* *}$ \\
Positive thyroid autoantibodies & $3.13(1.29-7.55)$ & $0.01^{*}$
\end{tabular}

OR odds ratio, $\mathrm{Cl}$ confidence interval, NIHSS National Institutes of Health Stroke Scale

**Highly significant; *Significant

negative group, with no difference in mortality rate at 1 year (Table 2 ).

Multivariable regression analysis for predictors of poor outcome at 1 year among acute stroke patients showed that higher NIHSS score at admission, subclinical hyperthyroidism, hypertension, atrial fibrillation, positive thyroid autoantibodies, and older age 
were significantly associated with poor outcome among acute stroke patients (Table 3).

Logistic regression analysis of risk factors predicting poor outcome in acute stroke patients showed that poor outcome was significantly and independently associated with higher NIHSS score at admission $(P=0.04)$, positive thyroid autoantibodies $(P=0.02)$, subclinical hyperthyroidism $(P=0.02)$, and atrial fibrillation $(P=0.01)$ (Table 4$)$.

\section{Discussion}

Acute stroke is a neurological emergency that can significantly affect the brain function and induce neuroendocrinal abnormalities [26]. Accurate identification of the predictors of stroke outcome might help ideal beginning time for immediate management. So, it is important to detect the new prognostic factors in addition to the already known to control them at an early stage, and help in improving outcomes of stroke patients [2]. Identification of the relationship between outcomes of stroke and subclinical thyroid dysfunction and thyroid autoantibodies might aid in supporting that thyroid dysfunction treatment might be a potential treatment to improve outcomes in stroke patients.

In this study, we found that, subclinical hyperthyroidism was found in $23 \%$ of patients, and subclinical hypothyroidism in $10 \%$ of patients. Euthyroidism was detected in $67 \%$ of patients. The patients with positive thyroid autoantibodies were commonly found in those with subclinical hyperthyroidism (28\%), followed by subclinical hypothyroidism (21\%) and euthyroidism (14\%). This was in agreement with Cho and colleagues, 2014 [23]. They found that stroke patients with elevated thyroid autoantibodies were the most commonly found in those with hyperthyroidism (27.8\%), followed by hypothyroidism (25.0\%) and euthyroidism (14.0\%).

Zhang and colleagues, 2019 [18]. They found that after admission, subclinical hypothyroidism, subclinical

Table 4 Logistic regression analysis of factors predicting poor outcome at 1 year in acute stroke patients

\begin{tabular}{|c|c|c|}
\hline $\begin{array}{l}\text { Risk factor of poor outcome in } \\
\text { acute stroke patients }\end{array}$ & $\begin{array}{l}\text { Odds ratio ( } 95 \% \\
\text { confidence Intervals) }\end{array}$ & $P$-value \\
\hline Older age & $1.06(1.02-1.09)$ & 0.05 \\
\hline Atrial fibrillation & $0.20(1.08-1.56)$ & $0.01^{*}$ \\
\hline Subclinical hyperthyroidism & $0.31(1.02-1.53)$ & $0.02^{*}$ \\
\hline Higher NIHSS score at admission & $1.09(1.11-2.36)$ & $0.04^{*}$ \\
\hline Positive thyroid autoantibodies & $1.61(1.03-2.74)$ & $0.02^{*}$ \\
\hline
\end{tabular}

*significant

NIHSS National Institute of Health Stroke Scale hyperthyroidism and euthyroidism were found in $17 \%$, $9.9 \%$ and $73 \%$ of stroke patients, respectively.

In concordance with the findings of Cho and colleagues, 2014 [23]. We found that higher NIHSS score at admission was observed in the positive thyroid autoantibody group than the negative thyroid autoantibody group. Also, we found higher final TSH level in the positive thyroid autoantibody group than the negative thyroid autoantibody group.

In our study, age, sex distribution, and serum FT3, FT4, and TSH levels did not differ between positive and negative thyroid autoantibody groups. $73 \%$ and $59 \%$ of stroke patients had poor outcomes (mRS was $>2$ ) at 3 months and 1 year respectively with no significant difference between ischemic and hemorrhagic stroke patients.

In the positive thyroid autoantibody group, disability at 1 year was significantly higher compared with the thyroid autoantibody negative group, with no difference in mortality rate at 1 year. These findings were in agreement with the findings obtained by Cho and colleagues, 2014 [23].

Therefore, based on the deleterious influence of thyroid autoantibodies on outcome, we assume that thyroid autoantibodies may affect poor outcome in acute stroke patients. This met with the finding of Zhang and colleagues, 2012 [3]. They found that elevated thyroid autoantibody, especially TPO-Ab, is associated with the development of intracranial stenosis in stroke patients.

Doing multivariable regression analysis for predictors of poor outcome at 1 year among acute stroke patients showed that that higher NIHSS score at admission, subclinical hyperthyroidism, hypertension, atrial fibrillation, positive thyroid autoantibodies, and older age were significantly associated with poor outcome among acute stroke patients. By logistic regression analysis, we found that poor outcome was significantly and independently associated with higher NIHSS score at admission, positive thyroid autoantibodies, subclinical hyperthyroidism, and atrial fibrillation.

In the same context Wollenweber and colleagues, 2013 [19] found that subclinical hyperthyroidism is a risk factor for poor outcome 3 months after ischemic stroke. Because subclinical hyperthyroid patients frequently (upwards of 50\%) and spontaneously revert to the euthyroid state over time (1-4 years) [27], the time to followup differed between our study and their study (1 year versus 3 months).

Inconsistence with our findings, subclinical hyperthyroidism increases the risk of atrial fibrillation which has an unfavorable short-term outcome. This can be attributed to that subclinical hyperthyroidism significantly reduced fibrinolytic capacity and increased sympathetic nervous system tone [28]. Other mechanisms to be 
considered are changes in coagulation parameters and an increase in energy and oxygen demand, which would be expected to impair ischemic tolerance in the brain [19].

Also, these findings were in agreement with the results obtained by Li and colleagues, 2019 [29]. They mentioned that stroke increasing in incidence with age and tends to present with more severe symptoms as well as outcomes in the elderly compared with younger patients. Aging may also influence the prognostic value of some known or possible predictors of outcome after stroke such as lower levels of total T3.

Inconsistence with our findings Zhang and colleagues, 2019 [30] found that adverse clinical outcome in acute ischemic stroke patients was significantly associated with higher NIHSS score and older age.

Moreover, the most likely speculation of the possible impact of thyroid autoimmunity on functional outcome is that immune-mediated vascular damage may contribute to the increased risk of poor outcome in stroke patients, by providing insufficient cerebral blood flow throughout the ischemic area. The presence of antigenic sites for thyroid autoantibodies on the cerebral vasculature may lead to cross-reactivity between vascular tissues and thyroid gland [6].

Both endothelial dysfunction and immune-mediated inflammatory reaction may be the crucial steps in the development of atherosclerosis [31, 32]. Endothelial dysfunction and resultant impairment of cerebral perfusion have the prognostic significance in the acute stage of ischemic stroke [33]. Moreover, thyroid autoantibodies were in association with the occurrence of intracranial arterial stenosis [3].

\section{Conclusions}

Subclinical hyperthyroidism and thyroid autoantibodies were associated with a poor outcome at 1 year in first-ever acute stroke patients especially in those presented with atrial fibrillation and higher NIHSS score at admission.

We recommend that if subclinical thyroid dysfunction is confirmed the patient should be referred to an endocrinologist for further diagnostic measures and treatment. Also, we recommend using thyroid autoantibodies values in predicting the outcomes of acute stroke patients especially in those presented with atrial fibrillation and higher NIHSS score at admission. These are easy methods in the prediction of outcomes of acute stroke. Future studies are recommended to determine whether the regulation of thyroid autoimmunity can improve functional outcome in stroke patients, which may help to support the possibility raised by the current study.

\section{Abbreviations}

CBC: Complete blood count; ESR: Erythrocyte sedimentation rate; FT3: Free triiodothyronine; FT4: Free thyroxin; TSH: Thyroid stimulating hormone; TPO-Ab: Thyroperoxidase autoantibodies; TG-Ab: Thyroglobulin autoantibodies; NIHSS: National Institute of Health Stroke Scale; mRS: Modified Rankin Scale; GCS: Glasgow Coma Scale; BMI: Body mass index; CT: Computed tomography; SD: Standard deviation; OR: Odds ratio; Cl: Confidence interval; SBP: Systolic blood pressure; DBP: Diastolic blood pressure; TC: Total cholesterol; LDL-C: Lowdensity lipoprotein cholesterol; HDL-C: High-density lipoprotein cholesterol; TG: Triglycerides

\section{Acknowledgements}

The authors acknowledge the subjects for their participation and cooperation in this study.

\section{Authors' contributions}

$\mathrm{RN}, \mathrm{AA}, \mathrm{HT}, \mathrm{GN}$ and $\mathrm{AO}$ carried out the work. RN designed the study, collected the patients, gathered clinical data, coordinated the research team, wrote the manuscript, had done the statistical analysis and reviewed the manuscript. GN coordinated the research team, and reviewed the manuscript. AO helped the laboratory work of the study. AA and HT had done the imaging work in the present study and reviewed the manuscript. All authors were involved in drafting the article or revising it critically for important intellectual content, and all authors approved the final version to be published. All authors read and approved the final manuscript.

Funding

There is no source of funding for the research.

\section{Availability of data and materials}

From the corresponding author.

\section{Declarations}

\section{Ethics approval and consent to participate}

The study was approved from the institute research board of Faculty of Medicine, Zagazig University, Egypt (ZU-IRB\#7007/23-6-2020). A written informed consent was obtained from all the participants or their responsible relatives (if the patient was unable to provide consent due to disturbed conscious level or weakness) after informing them about the study rationale and their right to withdraw from the study at any time without any consequences.

Consent for publication

All participants had signed an informed consent to participate and for the data to be published.

\section{Competing interests}

The authors declare that they have no competing interests.

\section{Author details}

${ }^{1}$ Faculty of Medicine, Zagazig University, Zagazig, Sharkia, Egypt. ${ }^{2}$ Suez Canal Authority, Ismailia, Egypt.

Received: 7 July 2021 Accepted: 21 December 2021

Published online: 06 January 2022

\section{References}

1. Adeloye D. An estimate of the incidence and prevalence of stroke in Africa: a systematic review and meta-analysis. PLoS ONE. 2014;9(6): e100724. https://doi.org/10.1371/journal.pone.0100724.

2. Al-Mufti F, Thabet AM, Singh T, El-Ghanem M, Amuluru K, Gandhi CD. Clinical and radiographic predictors of intracerebral hemorrhage outcome. Interv Neurol. 2018;7(1-2):118-36.

3. Zhang X, Chen Z, Shi Z, Lou M. Correlation between thyroid autoantibodies and intracranial arterial stenosis in stroke patients with hyperthyroidism. J Neurol Sci. 2012;318(1-2):82-4.

4. Kim SJ, Heo KG, Shin HY, Bang OY, Kim GM, Chung CS, Kim KH, Jeon P, Kim JS, Hong SC, Lee KH. Association of thyroid autoantibodies with 
moyamoya-type cerebrovascular disease: a prospective study. Stroke. 2010;41(1):173-6.

5. Pezzini A, Del Zotto E, Mazziotti G, Ruggeri G, Franco F, Giossi A, Giustina A, Padovani A. Thyroid autoimmunity and spontaneous cervical artery dissection. Stroke. 2006;37(9):2375-7.

6. Moodley K, Botha J, Raidoo DM, Naidoo S. Immuno-localisation of anti-thyroid antibodies in adult human cerebral cortex. J Neurol Sci. 2011;302(1-2):114-7.

7. Collet TH, Gussekloo J, Bauer DC, den Elzen WP, Cappola AR, Balmer P, lervasi G, Åsvold BO, Sgarbi JA, Völzke H, Gencer B, Maciel RM, Molinaro S, Bremner A, Luben RN, Maisonneuve P, Cornuz J, Newman AB, Khaw KT, Westendorp RG, Franklyn JA, Vittinghoff E, Walsh JP, Rodondi N. Thyroid Studies Collaboration. Subclinical hyperthyroidism and the risk of coronary heart disease and mortality. Arch Intern Med. 2012;172(10):799-809.

8. Biondi B, Cooper DS. The clinical significance of subclinical thyroid dysfunction. Endocr Rev. 2008;29(1):76-131.

9. Cooper DS, Biondi B. Subclinical thyroid disease. Lancet. 2012;379(9821):1142-54.

10. Cappola AR, Fried LP, Arnold AM, Danese MD, Kuller LH, Burke GL, Tracy RP, Ladenson PW. Thyroid status, cardiovascular risk, and mortality in older adults. JAMA. 2006;295(9):1033-41.

11. Humerah S, Siddiqui A, Khan HF. Pattern of altered lipid profile in patients with subclinical and clinical hypothyroidism and its correlation with body mass index. J Coll Physicians Surg Pak. 2016;26(6):463-6.

12. Eftekharzadeh A, Khamseh ME, Farshchi A, Malek M. The association between subclinical hypothyroidism and metabolic syndrome as defined by the ATP III criteria. Metab Syndr Relat Disord. 2016;14(3):137-44.

13. Owen PJ, Rajiv C, Vinereanu D, Mathew T, Fraser AG, Lazarus JH. Subclinical hypothyroidism, arterial stiffness, and myocardial reserve. J Clin Endocrinol Metab. 2006;91(6):2126-32.

14. Walsh JP, Bremner AP, Bulsara MK, O'Leary P, Leedman PJ, Feddema P, Michelangeli V. Subclinical thyroid dysfunction and blood pressure: a community based study. Clin Endocrinol (Oxf). 2006;65(4):486-91.

15. Popławska-Kita A, Siewko K, Telejko B, Modzelewska A, Myśliwiec J, Milewski R, Górska M, Szelachowska M. The changes in the endothelial function and haemostatic and inflammatory parameters in subclinical and overt hyperthyroidism. Int J Endocrinol. 2013;2013: 981638. https:// doi.org/10.1155/2013/981638.

16. Taylor PN, Albrecht D, Scholz A, Gutierrez-Buey G, Lazarus JH, Dayan CM, Okosieme OE. Global epidemiology of hyperthyroidism and hypothyroidism. Nat Rev Endocrinol. 2018;14(5):301-16.

17. Díez JJ, Iglesias P, Burman KD. Spontaneous normalization of thyrotropin concentrations in patients with subclinical hypothyroidism. J Clin Endocrinol Metab. 2005;90(7):4124-7.

18. Zhang X, Gong P, Sheng L, Lin Y, Fan Q, Zhang Y, Bao Y, Li S, Du H, Chen Z, Ding C, Wang H, Xu P, Zhang M, Scalzo F, Liebeskind DS, Xie Y, Liu D. Prognostic value of subclinical thyroid dysfunction in ischemic stroke patients treated with intravenous thrombolysis. Aging (Albany NY). 2019;11(17):6839-50.

19. Wollenweber FA, Zietemann V, Gschwendtner A, Opherk C, Dichgans M. Subclinical hyperthyroidism is a risk factor for poor functional outcome after ischemic stroke. Stroke. 2013;44(5):1446-8.

20. Pan SL, Wu SC, WuTH, Lee TK, Chen TH. Location and size of infarct on functional outcome of non-cardioembolic ischemic stroke. Disabil Rehabil. 2006;28(16):977-83.

21. Zhu J, Chen M, Li N, Yang S, Xu L, Wang Y, Li H. Correlation analysis of serum thyroid stimulating hormone with acute cerebrovascular disease. Eur J Med Res. 2019;24(1):35. https://doi.org/10.1186/s40001-019-0395-4.

22. Diaz-Olmos R, Nogueira AC, Penalva DQ, Lotufo PA, Benseñor IM. Frequency of subclinical thyroid dysfunction and risk factors for cardiovascular disease among women at a workplace. Sao Paulo Med J. 2010;128(1):18-23.

23. Cho HJ, Kim SS, Sung SM, Jung DS. Impact of thyroid autoantibodies on functional outcome in patients with acute ischemic stroke. J Stroke Cerebrovasc Dis. 2014;23(7):1915-20.

24. Fonarow GC, Saver JL, Smith EE, Broderick JP, Kleindorfer DO, Sacco RL, Pan W, Olson DM, Hernandez AF, Peterson ED, Schwamm LH. Relationship of national institutes of health stroke scale to 30-day mortality in medicare beneficiaries with acute ischemic stroke. J Am Heart Assoc. 2012;1(1):42-50.
25. New PW, Buchbinder R. Critical appraisal and review of the Rankin scale and its derivatives. Neuroepidemiology. 2006;26(1):4-15.

26. Bustamante A, Garcia-Berrocoso T, Llombart V, Simats A, Giralt D, Montaner J. Neuroendocrine hormones as prognostic biomarkers in the setting of acute stroke: overcoming the major hurdles. Expert Rev Neurother. 2014;14(12):1391-403.

27. Leonards CO, Schneider HJ, Liman TG, Fiebach JB, Endres M, Ebinger M. Thyroid-stimulating hormone, white matter hyperintensities, and functional outcome in acute ischemic stroke patients. Cerebrovasc Dis Extra. 2014;4(1):61-8

28. Erem C. Blood coagulation, fibrinolytic activity and lipid profile in subclinical thyroid disease: subclinical hyperthyroidism increases plasma factor $X$ activity. Clin Endocrinol (Oxf). 2006;64(3):323-9.

29. Li LQ, Xu XY, Li WY, Hu XY, Lv W. The prognostic value of total T3 after acute cerebral infarction is age-dependent: a retrospective study on 768 patients. BMC Neurol. 2019;19(1):54. https://doi.org/10.1186/ s12883-019-1264-Z.

30. Zhang S, Zhao X, Xu S, Yuan J, Si Z, Yang Y, Qiao S, Xu X, Wang A. Low free triiodothyronineis predicts worsen neurological outcome of patients with acute ischemic stroke: a retrospective study with bioinformatics analysis. BMC Neurol. 2019;19(1):272. https://doi.org/10.1186/s12883-019-1509-x.

31. Bonetti PO, Lerman LO, Lerman A. Endothelial dysfunction: a marker of atherosclerotic risk. Arterioscler Thromb Vasc Biol. 2003;23(2):168-75.

32. Ohashi R, Mu H, Yao Q, Chen C. Atherosclerosis: immunopathogenesis and immunotherapy. Med Sci Monit. 2004;10(11):255-60.

33. Rubin G, Firlik AD, Levy El, Pindzola RR, Yonas H. Relationship between cerebral blood flow and clinical outcome in acute stroke. Cerebrovasc Dis. 2000;10(4):298-306.

\section{Publisher's Note}

Springer Nature remains neutral with regard to jurisdictional claims in published maps and institutional affiliations.

\section{Submit your manuscript to a SpringerOpen ${ }^{\circ}$ journal and benefit from:}

- Convenient online submission

- Rigorous peer review

- Open access: articles freely available online

- High visibility within the field

- Retaining the copyright to your article

Submit your next manuscript at $\boldsymbol{\nabla}$ springeropen.com 